\title{
Successful intubation using video laryngoscope in a child with CHARGE syndrome - A case report -
}

\section{Jeongho Kim, Jeong In Hong, Kyoung-lin Chae, Kyoung Sub Yoon, Sang Yoong Park, Seung-Cheol Lee, Jong-Hwan Lee, Chan Jong Chung, and So Ron Choi}

Revised 1st, June 4, 2018

2nd, July 10, 2018

Accepted July 13, 2018

\section{Corresponding author}

So Ron Choi, M.D., Ph.D.

Department of Anesthesiology and Pain Medicine, Dong-A

University School of Medicine, 32

Daesingongwon-ro, Seo-gu, Busan

49201, Korea

Tel: 82-51-240-5390

Fax: 82-51-247-7819

E-mail: choisr@dau.ac.kr

ORCID

https://orcid.org/0000-0002-4173-8939
Department of Anesthesiology and Pain Medicine, Dong-A University School of Medicine, Busan, Korea

\begin{abstract}
CHARGE syndrome is a rare genetic disorder with CHD7 gene mutation. CHARGE is an acronym for coloboma $(C)$, heart disease $(H)$, atresia of choanae $(A)$, retardation of growth $(R)$, genitourinary malformation $(G)$, and ear abnormalities $(E)$. Patients with CHARGE syndrome need to undergo many surgeries due to their various congenital anomalies. Since airway abnormalities frequently accompany CHARGE syndrome, general anesthesia remains a challenge. Here we report a case of difficult intubation in a 35-month-old boy with CHARGE syndrome during general anesthesia and the experience of successful intubation using D-blade of C-MAC ${ }^{\circledR}$ video laryngoscope.
\end{abstract}

Keywords: Airway management; CHARGE syndrome; Laryngoscope; Pediatrics.
CHARGE syndrome is a rare autosomal dominant inherited disorder with $\mathrm{CHD} 7$ gene mutation. It was first described by Hall [1] in 1979. It was named by Pagon et al. [2] in 1981. CHARGE is an acronym for coloboma $(\mathrm{C})$, heart disease $(\mathrm{H})$, atresia of choanae (A), retardation of growth (R), genitourinary malformation $(\mathrm{G})$, and ear abnormalities (E). Patients with CHARGE syndrome need to undergo many surgeries in the neonatal period, since they have various congenital anomalies. Since airway abnormalities frequently accompany CHARGE syndrome, general anesthesia remains a challenge [3]. Here we report a case of a difficult intubation in a 35-month-old boy with CHARGE syndrome during general anesthesia and the experience of successful intubation using a video laryngoscope.

\section{CASE REPORT}

A 35-month-old boy was admitted to our hospital for the implant of left cochlea in 2017. He had been born in 2014 by vaginal delivery at 38 weeks of gestational age. At birth, he had been diagnosed with CHARGE syndrome. He had a surgical history for correction of atresia of choanae at another hospital; however, we could not access his medical records.

He was first admitted to our hospital in 2016 for the implant of right cochlea. At that time in this hospital, there were no special tools for difficult intubation of a child. We explained to his parents that there were several situations in which, if we could not ventilated the child, an emergency tracheostomy might be necessary, and if we could not intubate, we would have no choice but to postpone the surgery. Five wellexperienced anesthesiologists tried intubation using a Macintosh laryngoscope about ten times but failed due to bilateral tonsillar hypertrophy and a very small epiglottis. Fortunately, despite the grade 3 Cormack-Lehane classification, we could ventilate the child with a facial mask. Other attempts using a conventional blade of C-MAC ${ }^{\circledR}$ video laryngoscope (Karl

This is an Open Access article distributed under the terms of the Creative Commons Attribution Non-Commercial License (http://creativecommons.org/licenses/by-nc/4.0) which permits unrestricted non-commercial use, distribution, and reproduction in any medium, provided the original work is properly cited. 
Storz, Germany) and fiberoptic bronchoscope (Olympus Ltd., Japan) failed. These were designed for adult patients and were too big for the child. After one hour of several attempts, intubation was done successfully by laryngoscope with a straight blade using a wire-reinforced $4.5 \mathrm{~mm}$ internal diameter endotracheal tube.

In the preoperative evaluation for the implant of left cochlea, we discovered that he had growth and mental retardation, microtia, and postnasal drip. His weight was $11 \mathrm{~kg}(0.44$ percentile) and his height was $90 \mathrm{~cm}$ (7.8 percentile). In airway evaluation, a small mouth and micrognathia were identified. His Mallampati score was 3. For better airway management, we prepared a C-MAC ${ }^{\circledR}$ video laryngoscope with D-blade for pediatrics (Karl Storz). After induction with ketamine $20 \mathrm{mg}$ and rocuronium $6 \mathrm{mg}$ by intravenous injection, we tried intubation using the video laryngoscope. Still, there was tonsillar hypertrophy. Although we kept trying to insert the blade, we could not identify the epiglottis due to anterior location of the larynx. However, arytenoid cartilages and the opening of the glottis were identified on a monitor (Fig. 1). Intubation using wire-reinforced $4.5 \mathrm{~mm}$ internal diameter endotracheal tube was performed. However, due to the anterior location of larynx and acute angle of video laryngoscope, the tip of tube could not enter the trachea. A backward upward rightward pressure (BURP) maneuver was also performed. It also failed, since larynx did not move. In another intubation attempt, after entering the larynx, the tube was rotated $180^{\circ}$ to enter the glottis, and the intubation was successful (Fig. 2). Two days later, a left mastoid exploration was performed for left facial palsy. Intubation using a D-blade of C-MAC ${ }^{\circledR}$ video

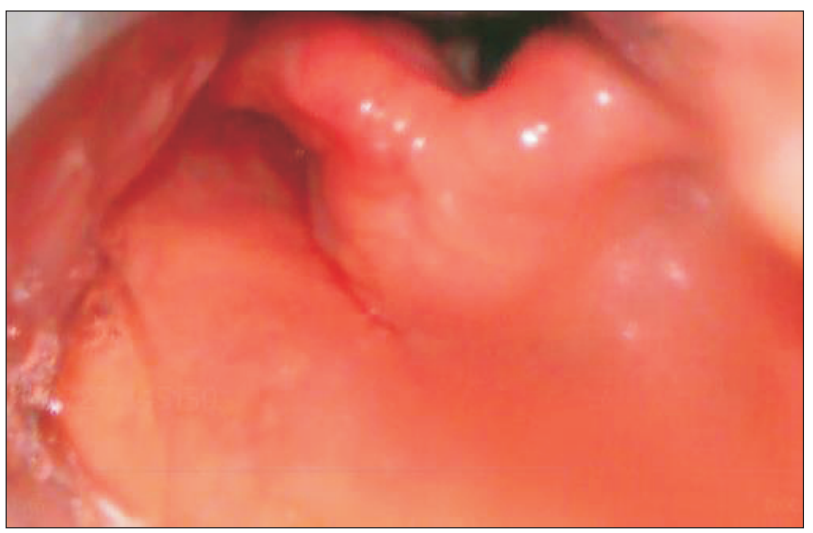

Fig. 1. Arytenoid cartilages and opening of glottis were identified on a monitor of the C-MAC ${ }^{\circledR}$ video laryngoscope. laryngoscope was also successfully performed with the rotating tube method.

\section{DISCUSSION}

The incidence rate of CHARGE syndrome is presumed to be $0.1-1.2 / 10,000$ live births [3]. Coloboma and other ocular abnormalities are reported in $75-90 \%$ of CHARGE syndrome patients. Cardiac malformation is reported in $75-85 \%$ of all cases, while choanal atresia is reported in $65 \%$ of all cases [4]. Craniofacial anomalies, micrognathia, anterior larynx, cleft palate, and enlarged tonsils and adenoid often accompany CHARGE syndrome, leading to many airway problems. Upper airway collapse or subglottic stenosis due to laryngomalacia can also occur [5]. Tracheostomy is necessary for $29 \%$ of patients [6]. As seen above, in treating CHARGE syndrome patients, general anesthesia and perioperative airway management are persistent challenges. Many attempts have been made to overcome these issues. Hara et al. [7] have tried the laryngeal mask airway (LMA) in CHARGE syndrome patients and found it to be successful. They have reported that since CHARGE syndrome patients have smaller pharynges and larynges than normal children, a smaller LMA should be used first. However, in some types of surgery, successful LMA insertion is difficult. We also had to turn the head to a lateral position for the cochlear implant. The use of LMA was limited to due to the long operation time. In our hospital, it took three hours for the right cochlear implant and three hours 55 minutes for the left cochlear implant. Shimizu et al. [8] have reported a successful intubation case

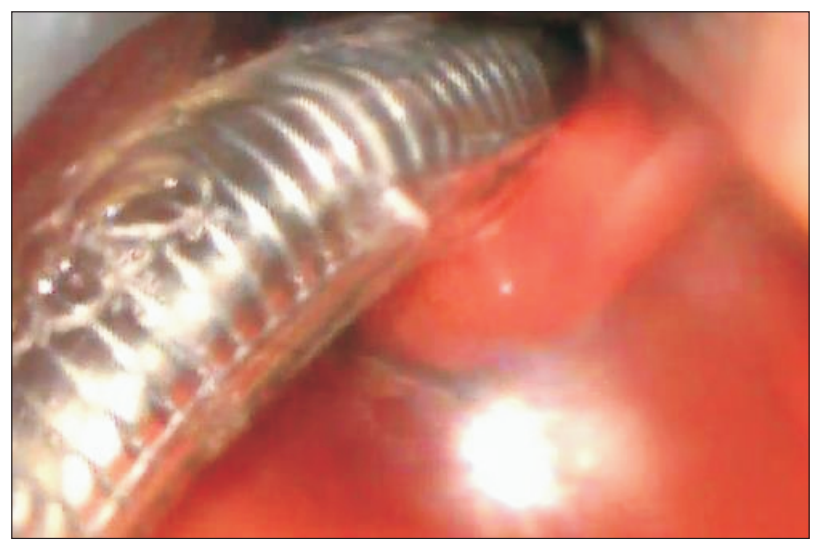

Fig. 2. After entering larynx, tube was rotated $180^{\circ}$ to enter glottis due to anterior location of larynx and acute angle of video laryngoscope. 
using GlideScope ${ }^{\circledast}$ (Verthon, USA). They mentioned that this tool is useful for difficult airway management due to an upper airway malformation. Use of a GlideScope ${ }^{\circledast}$ for intubation in CHARGE syndrome patients has also been reported to be successful [9]. We used C-MAC ${ }^{\circledast}$ with a D-blade for pediatrics, which is similar to a GlideScope ${ }^{\circledR}$. The use of the C-MAC ${ }^{\circledast}$ video laryngoscope in the setting of a predicted difficult airway has resulted in an improved laryngeal image and a higher success rate of tracheal intubation than in direct laryngoscopy [10]. Teoh et al. [11] has reported that C$\mathrm{MAC}^{\circledR}$ has the easiest blade insertion. It gave the best clarity of laryngeal views, prevented fogging of the lens, and offers automatic white balance. The D-blade, which was essentially designed for management of difficult airways, is half-moon shaped with increasing blade angulations from $18^{\circ}$ to $40^{\circ}$. The high blade angulation enables optimal glottic visualization in almost all patients [12]. It may also prevent the need for additional maneuvers and further extension of the head [13]. However, it has limitations, such as longer intubation time and difficult tube passage. Due to the anterior location of the larynx, large tonsils, acute angle of C-MAC ${ }^{\circledR}$ video laryngoscope, and failure of BURP maneuver, several attempts may be needed for successful intubation, even with the use of C$\mathrm{MAC}^{\circledast}$. Since the blade is angled more, the tip of the intubation tube has to be directed to the larynx at a right angle. This leads to difficulty in passage or in navigation of the endotracheal tube toward the larynx, despite adequate visualization of the glottis [13]. Sun et al. [14] have found that the hockeystick-like J-curvature of the stylet at the end of the tube, with the tube passed from the lateral side of the patient's mouth, is more successful for placing the tip of the endotracheal tube in the glottis. We also made a tube with a stylet shaped like a hockey stick. However, the intubation failed. After we rotated the tube clockwise, we intubated successfully. Despite these limitations, a better view was obtained with the C-MAC Dblade than with the direct laryngoscope, and we achieved excellent visualization of the glottic opening, resulting in a high success rate.

In conclusion, many surgical interventions are required for CHARGE syndrome patients. Since airway abnormality is present in many cases, preoperative airway evaluation is very important. For difficult intubation, it should be kept in mind that LMA or video laryngoscope could be used. Though tracheostomy is safe, it could be invasive. Therefore, we recom- mend using a video laryngoscope since it is non-invasive and useful. It seems to be the best option for successful intubation in patients with CHARGE syndrome.

\section{CONFLICTS OF INTEREST}

No potential conflict of interest relevant to this article was reported.

\section{ORCID}

Jeongho Kim: https://orcid.org/0000-0003-4447-2838

Jeong In Hong: https://orcid.org/0000-0002-9487-3368

Kyoung-lin Chae: https://orcid.org/0000-0001-9132-8279

Kyoung Sub Yoon: https://orcid.org/0000-0003-1957-252X

Sang Yoong Park: https://orcid.org/0000-0001-7495-8025

Seung-Cheol Lee: https://orcid.org/0000-0001-8669-5517

Jong-Hwan Lee: https://orcid.org/0000-0002-9130-9833

Chan Jong Chung: https://orcid.org/0000-0002-0236-7135

\section{REFERENCES}

1. Hall BD. Choanal atresia and associated multiple anomalies. J Pediatr 1979; 95: 395-8.

2. Pagon RA, Graham JM Jr, Zonana J, Young SL. Coloboma, congenital heart disease, and choanal atresia with multiple anomalies: CHARGE association. J Pediatr 1981; 99: 223-7.

3. Blake KD, Prasad C. CHARGE syndrome. Orphanet J Rare Dis 2006; $1: 34$.

4. Hsu P, Ma A, Wilson M, Williams G, Curotta J, Munns CF, et al. CHARGE syndrome: a review. J Paediatr Child Health 2014; 50: 504-11.

5. Stack CG, Wyse RK. Incidence and management of airway problems in the CHARGE association. Anaesthesia 1991; 46: 582-5.

6. Roger G, Morisseau-Durand MP, Van Den Abbeele T, Nicollas R, Triglia JM, Narcy P, et al. The CHARGE association: the role of tracheotomy. Arch Otolaryngol Head Neck Surg 1999; 125: 33-8.

7. Hara Y, Hirota K, Fukuda K. Successful airway management with use of a laryngeal mask airway in a patient with CHARGE syndrome. J Anesth 2009; 23: 630-2.

8. Shimizu S, Koyama T, Mizota T, Fukuda K. Successful tracheal intubation with the GlideScope ${ }^{\circledR}$ in a patient with CHARGE syndrome. J Anesth 2013; 27: 965-6.

9. Sarıçiçek V, Mızrak A, Şahin M, Göksu S, Gül R, Cesur M. Glidescope video laryngoscope use for tracheal intubation in a patient 
with CHARGE syndrome. Turk J Anaesthesiol Reanim 2014; 42: 352-4.

10. Kang BJ, Seo HS, Lee SH. Successful use of C-MAC ${ }^{\circledR}$ video laryngoscope following failure of multiple intubation attempts during laryngomicroscopic surgery in an infant - a case report -. Anesth Pain Med 2017; 12: 339-41.

11. Teoh WH, Saxena S, Shah MK, Sia AT. Comparison of three videolaryngoscopes: pentax airway scope, C-MAC, glidescope vs the macintosh laryngoscope for tracheal intubation. Anaesthesia 2010; 65: 1126-32.

12. Cavus E, Neumann T, Doerges V, Moeller T, Scharf E, Wagner K, et al. First clinical evaluation of the C-MAC D-Blade videolaryngoscope during routine and difficult intubation. Anesth Analg 2011; 112: 382-5.

13. Kılıçaslan A, Topal A, Erol A, Uzun ST. Comparison of the C-MAC D-Blade, conventional C-MAC, and macintosh laryngoscopes in simulated easy and difficult airways. Turk J Anaesthesiol Reanim 2014; 42: 182-9.

14. Sun DA, Warriner CB, Parsons DG, Klein R, Umedaly HS, Moult $\mathrm{M}$. The glidescope video laryngoscope: randomized clinical trial in 200 patients. Br J Anaesth 2005; 94: 381-4. 